in establishing the isostatic theory on a firm basis. This point, for which there is no direct evidence in the Norwegian case, is to the effect that the tilting of the Great Lakes region was in progress before and during the rise of the sea in the Ottawa valley, for, presumably from a comparison of contemporaneous ice-margins, it is concluded that "the Ottawa valley must have been, in part at least, occupied by the icesheet during the existence of Lakes Iroquois and Algonquin, and at least a small amount of uplift affected the region at the foot of Lake Ontario during the life of Lake Iroquois. Uplift also affected the northern portion of the Great Lakes region, and probably included the upper portion of the Ottawa valley near Mattawa during the existence of Lake Algonquin, and while the ice-sheet still occupied the upper portion of the Ottawa valley." Further, it is not a case of alternating elevation and depression, "for the result of investigations by numerous geologists of the raised beaches of the Great Lakes region has shown that differential uplift took place almost continuously as the ice withdrew."

We have thus direct proof that a district which was rising relatively to those around it was nevertheless undergoing submergence beneath the level of the sea. This remarkable phenomenon can have but one explanation, namely, that the isostatic recovery and the general rise of the ocean-level were in progress simultaneously, and that for a time the latter was the more rapid. Norway up to the present has only supplied a measure of the difference of these two motions. To presume their concerted action was a leap in the dark. Canada has now produced unexpected evidence of their individual existence.

There is now but one thing wanting to make the analogy between the isostatic phenomena of America and Europe perfect in every detail, and that is the discovery of a shore-line corresponding to the "Early Neolithic" or "Littorina-Tapes" raised beaches of Great Britain and Scandinavia. This should represent in the south a distinct resubmergence, and in the north a pronounced check or slowing down in the general emergence. W. B. WRIGHT.

\section{PLANT DISEASES.}

THE rôle played by insects in the spread of plant diseases is well brought out in the case of the collar-rot of rubber trees (Hevea brasiliensis), recently investigated by Sharples (Bull. 25, Dept. of Agriculture, Federated Malay States, 1916). The disease is caused by the fungus Ustulina zonata, as Brooks (Bull. 22, F.M.S.) has already shown. Sharples finds that at the time when the trees in a young rubber plantation are thinned out, at the age of about six or seven years, attacks by boring beetles (Xyleborus parvulus) become very common. He shows that these insects easily enter trees the bark of which has been injured by the falling of one tree against another. Attacks by the above-mentioned fungus usually quickly follow the beetles which enter rubber trees, the tracks of the insects being convenient ports of entry for the wound-parasite, $U$. zonata. At the time of thinning a large amount of suitable food material for the fungus is available in the form of soft rubber wood. Owing to the increased development of the fungus under these conditions in conjunction with the greater prevalence of borer attacks during the same period, it follows that the thinning-out stage is the most dangerous one in the life of a plantation as regards the attacks of this fungus on rubber trees.

To No. ro of the twelfth volume of the South African Journal of Science, published in May of the present year, Dr. Ethel M. Do:dge contributes a paper on the occurrence in South Africa of Bacterium campestre, the organism which causes the black-rot disease of the cabbage and other cruciferous crops. This organism had formerly been recorded only from Europe, America, and New Zealand, but Miss Doidge's investigations showed that the disease caused by it was quite common in the neighbourhood of Pretoria. The most interesting point about the communication is that it seems clear that the organism in the case under consideration was introduced into South Africa on cabbage seed which came from England. From cabbage seeds imported by the nuseryman to whose premises the diseased plants first observed by Miss Doidge were traced, the organism was isolated and its virulence proved by the successful artificial inoculation of two healthy cabbage plants. It was suggested nearly twenty years ago by Stewart in America that this disease was probably disseminated by seedsmen, but actual proof was then wanting. Soon after this the organism was isolated by Harding from the surface of cabbage seed produced by diseased plants in Long Island; and now Miss Doidge has shown that by such means the disease may be carried from one continent to another. Soaking suspected seed for fifteen minutes in $I: 240$ formalin or in I : 1000 mercuric chloride is recommended as a suitable method of treatment.

The cause of the serious disease of the potato known as the "Blattrollkrankheit" (leaf-roll disease) has been a matter of considerable controversy. The earlier investigators regarded the disease as being due to the choking of the wood-vessels of the plant with fungus mycelium. Recent researches, however, have shown that plants suffering from the choking of their vessels (hadromycosis) are not to be confounded with those affected with the true leaf-roll disease in which mycelium is absent. Quanjer, in.1913, found necrosis of the phloem to be a characteristic symptom of true leafroll in Holland; and in his most recent publication (Med. van d. Rijks Hoogere Land-, Tuin- en Boschbouwschool, Deel x., Wageningen, 1916) this author claims to have proved that the disease is due to a transmissible virus. Since attempts made to infect healthy potato plants by means of injections of the sap of diseased plants did not succeed, it might be thought that the claim is not justified. However, successful transmission of the disease was brought about in grafting experiments both with stalks and with tubers. Further evidence in favour of the virus is claimed to be afforded by the failure to isolate any parasitic organisms from affected plants, by the method of spread of the disease, by the uncertain results of selection as a means of raising healthy stocks of plants, and by the infection of healthy plants when transferred to diseased surroundings either through the agency of the soil (in which it is believed that the virus is often present) or from neighbouring diseased plants. It would seem that further research is necessary in order to supply absolutely convincing proof of the virus theory of the origin of this disease. Should it turn out to be a correct one, this disease, which has already made its appearance in some parts of Great Britain, will probably become more or less widespread in a few years unless some measures are taken to check it. The publication referred to is published in both the Dutch and the English languages.

COAL AND ITS ECONOMIC UTILISATION. THE economic importance of coal we perhaps realise. It is the only raw material we produce in great quantity; the value of our total mineral output in 1913 was above $160,000,000 l$. ; of this the value of the coal at the mine was above 145,500 ,oool.

Our output of coal and our home consumption in

1 Abridged from the Howard Lectures delivered before the Royal Society of Arts on November 27, December 4, and December 11, 1916, by Prof $J$ S. S. Hirame. NO. 2469 , VOL. 987 